Hydrology and Earth System Sciences, 3(1), 137-149 (1999) (C) EGS

\title{
The UP modelling system for large scale hydrology: simulation of the Arkansas-Red River basin
}

\author{
C.G. Kilsby, J. Ewen, W.T. Sloan, A. Burton, C.S. Fallows and P.E. O'Connell
}

Water Resource Systems Research Laboratory, Department of Civil Engineering, University of Newcastle, Newcastle upon Tyne, NE1 7RU, UK. email: c.g.kilsby@ncl.ac.uk

\begin{abstract}
The UP (Upscaled Physically-based) hydrological modelling system to the Arkansas-Red River basin (USA) is designed for macroscale simulations of land surface processes, and aims for a physical basis and, avoids the use of discharge records in the direct calibration of parameters. This is achieved in a two stage process: in the first stage parametrizations are derived from detailed modelling of selected representative small catchments and then used in a second stage in which a simple distributed model is used to simulate the dynamic behaviour of the whole basin. The first stage of the process is described in a companion paper (Ewen $e t$ al., this issue), and the second stage of this process is described here. The model operates at an hourly time-step on 17-km grid squares for a two year simulation period, and represents all the important hydrological processes including regional aquifer recharge, groundwater discharge, infiltration- and saturation-excess runoff, evapotranspiration, snowmelt, overland and channel flow. Outputs from the model are discussed, and include river discharge at gauging stations and space-time fields of evaporation and soil moisture. Whilst the model efficiency assessed by comparison of simulated and observed discharge records is not as good as could be achieved with a model calibrated against discharge, there are considerable advantages in retaining a physical basis in applications to ungauged river basins and assessments of impacts of land use or climate change.
\end{abstract}

\section{Introduction}

This paper describes the application of the UP hydrological modelling system to the Arkansas-Red River basin as part of the UK NERC Terrestrial Initiative in Global Environmental Research (TIGER) and GEWEX Continental International Project (GCIP). The UP modelling system (Upscaled Physically-based) is designed for macro-scale simulations of land surface processes, both as stand-alone studies and coupled to an atmospheric model. The theory underlying the UP model has been described in Ewen (1997), and the practice of parametrization has been illustrated in a companion paper in this volume (Ewen et al., 1999). UP is designed to be used as a tool for modelling the land phase of the hydrological cycle and the impacts of climate variability and land use change, to be carried out consistently at both the small (catchment) scale and large scale (major river basins or continents). UP differs from most macroscale hydrological models in that it retains a physical basis in its parametrizations without sacrificing computational speed, giving results which are properly sensitive to changes in physical properties and inputs measured (or predicted) over a wide range of scales, from the point scale upwards. This is achieved in a two stage process: a simple distributed simulation model for the whole basin is run using parametrizations derived from detailed modelling at selected representative small catchments. The simple structure of the model then allows it to be coupled directly to existing climate and weather forecasting models.

\section{Objectives}

The overall objective is to simulate the water budget and hydrological processes of the entire Arkansas-Red River Basin (ARRB) with a modelling system which is computationally efficient and simple and yet retains a physical basis. A full range of hydrological variables should be consistently simulated at both the catchment and continental scales. The system should be sensitive to climate and land use changes, and be able to be coupled to an atmospheric model. The system should account for all the important hydrological processes, including runoff generation, infiltration, percolation, evapotranspiration, snowmelt and groundwater processes. The time and space scales chosen for the application are a one hour timestep and a $17 \mathrm{~km} \times$ $17 \mathrm{~km}$ grid size. This is the grid size presently used in the 
Unified Model of the UK Meteorological Office in mesoscale configuration. The application described in this paper, therefore, differs in several key respects from previous attempts to model macro-scale river basins.

There has been a number of recent hydrological simulations of the ARRB. Abdulla and Lettenmaier $(1997 a, b)$ applied a grid version of the two-layer variable infiltration capacity model (VIC-2L) at $1^{\circ}$ spatial resolution and daily time resolution. In their approach, discharge data were used directly to estimate seven of the nine model parameters for 34 calibration catchments with a least squares technique. The parameters were then regionalised to provide coverage for the whole basin. Similarly, the PILPS-2c workshop (Project for Intercomparison of Land Surface Parametrization Schemes, Lohmann et al., 1998) evaluated a number of hydrological models used as land surface schemes for atmospheric models. PILPS 2-c models again used $1^{\circ}$ grid boxes, and river discharges were used directly for calibration of model parameters. The models ranged from simple 'bucket' schemes to very complex SoilVegetation-Atmosphere schemes (SVATs) with multilayer canopies. The majority of the models used in PILPS can be characterised by their approach of using a onedimensional point representation of hydrological prôcesses applied at the grid scale, with no account taken of heterogeneity or lateral water movements. Those models allowing for some heterogeneity (at least to some degree) rely on direct calibration of parameter values.
The conclusions of PILPS $2 \mathrm{c}$ were clear-that model calibration is desirable since 'calibrated models performed better not only for the calibration and verification catchments, but at the regional scale'. Whilst this may be justifiable on narrow model performance grounds, the UP approach rejects the idea that calibration is desirable in itself, since it imposes a number of restrictions. Firstly, unless the model parametrization represents all of the important hydrological processes, one set of parameters cannot be transferred reliably to another application region without re-calibration. This may not be possible or practical in cases of data scarcity or for ungauged catchments (large parts of the globe). If the model does represent all of the important hydrological processes, then serious difficulties in calibrating a large number of inter-related parameters are likely to be encountered. Secondly, the calibrated parameter set is valid only for hydrological regimes encountered within the calibration procedure, and so may not be used reliably for studies of climate or land use change.

A further important issue raised by PILPS $2 \mathrm{c}$ was 'how to transfer calibration information between scales'. This is certainly a problem for a calibration-based approach; how far it remains a problem for a physically-based approach such as UP is one of the issues explored in this paper.

There are three fundamental differences from previous work in the present application. Firstly, relatively high spatial and temporal resolution is employed, and sub-grid variability in hydrological processes is retained. This is

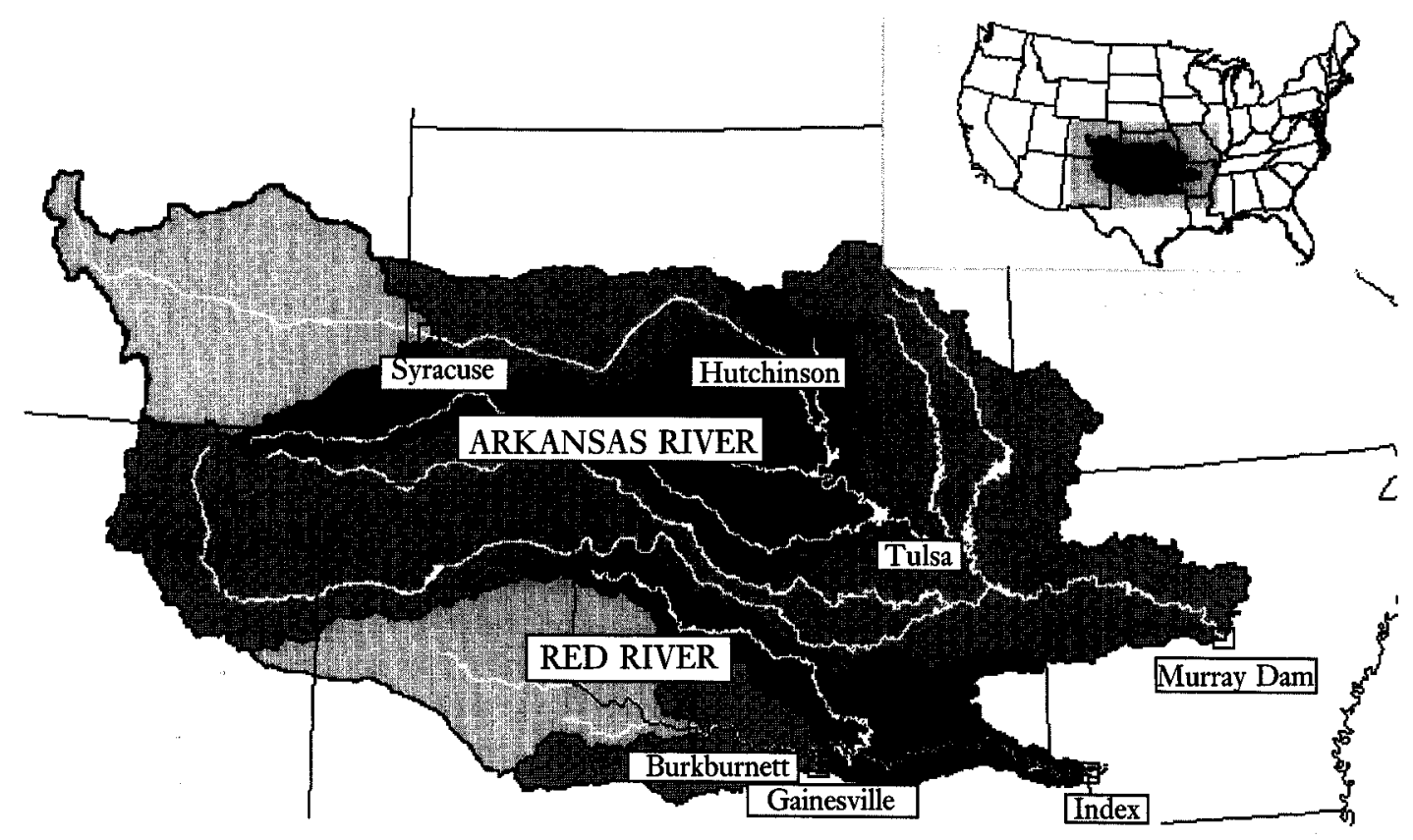

Fig. 1. Map of the Arkansas-Red River basin showing the major rivers, the seven streamflow gauges used for routing flows and the catchment areas associated with them. The location of the Arkansas-Red River and the domain of the Unified Model are shown in the inset diagram. 
essential as the runoff dynamics resulting from high intensity convective rainfall occur at small space and time scales. Secondly, a physical basis is maintained; calibration of model parameters against measured discharge is avoided. Thirdly, regional groundwater systems are considered.

\section{Study area-the Arkansas-Red River basin}

The ARRB provides a hydrologically diverse and demanding application. The basin covers some $570,000 \mathrm{~km}^{2}$ from the Rocky mountains in the west, through the Great Plains, discharging to the Mississippi River in the east (see Fig. 1).

\section{PHYSIOGRAPHY AND GEOLOGY}

Elevation ranges from some $90 \mathrm{~m}$ in the east of the basin to over $4000 \mathrm{~m}$ in the Rocky mountains to the west. The east of the basin comprises the Ouachita mountains (elevation range from some $90-400 \mathrm{~m}$ ) and Ozark plateau, while the major, central part of the basin consists of the southern Great Plains.

There are several major regional aquifer systems underlying the ARRB. One of these, the High Plains aquifer which underlies the Great Plains region, outcrops extensively and another, the Ozark Plateau aquifer, outcrops to a lesser extent. In addition to the major regional aquifers, there are several exposed, permeable sandstone and limestone beds, which form aquifers mainly in the central lowlands; however they are not hydraulically connected to one another and their lateral extent is insufficient for them to be considered major regional aquifers. They do, however, form an important part of the hydrological cycle at the local, or sub-basin, scale.

In the part of the High Plains aquifer underlying the ARRB, the principal geological unit is Tertiary and is called the Ogallala Formation. It consists of poorly sorted clay, silt, and unconsolidated gravel and has a maximum thickness of $280 \mathrm{~m}$. This overlies a bedrock which is predominantly consolidated beds of clay, volcanic ash and fine sands. At the regional scale, the aquifer can be considered to be unconfined. Groundwater in the High Plains aquifer generally tends to move from west to east at an average rate, estimated by Gutentag et al. (1984), at $30 \mathrm{~cm}$ per day. It discharges naturally into streams and seeps out along the eastern escarpment often tens of kilometres from where it entered the aquifer. Streams which originate on the high plains tend to be ephemeral in their upper reaches and perennial where their channels are incised to the water table. Some major rivers of the region are incised to the bedrock. The aquifer provides an abundant and easily accessible source of water and is pumped to provide irrigation water for farming.
The hydrogeology of the Ozark plateau aquifer system is very different to that of the High Plains aquifer. Here, the aquifer system consists mainly of carbonate rocks and contains extensive areas of karst. Most of the water that percolates to the saturated zone moves laterally, at a much faster rate than that associated with the High Plains aquifer, through shallow, local flow systems; it then discharges into streams as baseflow or via springs. As a consequence of this localised behaviour, the UP model represents the Ozark plateau aquifer system as a patchwork of local aquifers.

\section{CLIMATE}

Annual rainfall is around $1500 \mathrm{~mm}$ in the east, giving a humid temperate climate associated with the main moisture supply from the Gulf of Mexico. Annual rainfall decreases towards the west, falling to below $400 \mathrm{~mm}$ in the semi-arid Great Plains. Here, 60 to $80 \%$ of rain falls between April and September, mostly in thunderstorms. In the Southern Rocky Mountains, at the Western extreme of the basin, rainfall is rather higher, with most precipitation occurring as snowfall in the winter months.

Mean annual temperatures range from around $18{ }^{\circ} \mathrm{C}$ in eastern parts of the basin to around $10{ }^{\circ} \mathrm{C}$ on the Plains at the base of the Rockies. Summer temperatures in the mountains are generally high enough to melt the extensive winter snowpack completely.

In the Great Plains, clear skies, low humidity and high temperatures lead to large evaporation. Potential evaporation generally exceeds average annual precipitation in western parts of the basin. Runoff is, therefore, limited and aquifer recharge is likely to occur only in winter during prolonged periods of rainfall. Evaporation rates remain high towards the east, although the higher rainfall totals ensure aquifer recharge and surface runoff into rivers. In the Rockies, steep slopes, orographically enhanced precipitation and thin soils produce larger runoff volumes than on the adjacent Plains.

\section{LAND USE}

The vegetation of the Arkansas and Red River basins varies largely in response to the regional precipitation gradient and is clearly described by Vankat (1979). Undeveloped montane coniferous forest covers much of the Rocky Mountains. To the east, the forests give way to natural grasslands, whose density depends on the trend in rainfall. Agriculture is found in pockets along the river valleys and where irrigation is possible.

Moving eastwards, a greater diversity of medium and tall grasses occurs. Agriculture (including winter wheat) forms a substantial fraction of land use, largely supported by irrigation. Deciduous trees, notably oak, appear in the east in response to the higher rainfall. Temperate forest dominates the eastern landscape with well-developed 
forests in the Ouachita Mountains and on the Ozark Plateau. The forests contain a mixture of evergreen and deciduous species and agriculture is only a minor form of land use in the east of the basin.

\section{Data sources}

Many data sources and types were used in the application. The GCIP CD-ROM datasets are an excellent starting point and provide a benchmark for future studies of this kind. Several other sources for more localised information were found necessary. Data collation, processing and coordinate transformation were performed under the Geographical Information System GRASS.

\section{ELEVATION}

A basin-wide digital elevation model (DEM) at $500 \mathrm{~m}$ resolution was available from the GCIP GREDS CD-ROM. This was sufficient for classification of the basin and meteorological analysis. However, more detailed hydrological analysis was required for parametrization. DEMs at $100 \mathrm{~m}$ resolution were, therefore, constructed using a tensioned spline surface fitting routine in GRASS for the parametrization catchments using USGS $1: 100,000$ contour data. The DEMs were subjected to validation checks including elevation distribution analysis, manual comparison with contours and removal of pits.

\section{LAND COVER}

A one-kilometre data base of land cover characteristics is available for the United States, generated from the classification of Advanced Very High Resolution Radiometer (AVHRR) time series data sets (Loveland et al., 1991). The data base includes land cover definition, derived from image classification and post-classification using elevation, eco-regions and frost-free period refinement. This results in 159 seasonally distinct land cover regions. Reclassification to 28 categories provides a more useful data set, based on the vegetation and land cover classification of the Biosphere-Atmosphere Transfer Scheme (Dickinson et al., 1986). An alternative, simpler classification is provided by Running et al.(1995), producing water and seven land cover types.

Three further data sets obtained from the same data base were used in the project. The onset of greenness data set consists of the first bi-weekly period in which significant development of standing green biomass occurred. The peak of greenness data set contains the biweekly period in which the highest level of greenness was recorded. The final data set comprises the duration of greenness in days.
SOILS

A multi-layer soil characteristics data set, based on the USDA State Soil Geographic Database (STATSGO), was used (Miller and White, 1998); incorporates eleven standard layers, providing information up to a maximum of 2.5 metres depth, for a number of different parameters including dominant soil texture class, relative proportions of sand, silt and clay and available water content. Porosity data, derived from bulk density and particle density, were also available and a single-layer data set of depth to the bedrock.

\section{HYDROGEOLOGY}

The hydrogeology of the regional aquifers underlying the ARRB is outlined in a report by the United States Geological Survey (USGS) (Jorgensen et al., 1993). This was compiled from a number of more detailed, earlier studies by the USGS (e.g. Gutentag et al., 1984). Maps of hydrogeological properties from these studies were digitised for use in UP's regional groundwater model.

\section{METEOROLOGICAL DATA}

Meteorological data were obtained via the On-line Access and Service Information System (OASIS) of the National Climatic Data Center (Snodgrass and Faas, 1992). OASIS contains two databases compiled by the National Weather Service, a full set of hourly surface meteorological observations for around 1200 sites in North America and hourly precipitation data for much of the United States.

Hourly meteorological records for the simulation period $(01 / 06 / 94-31 / 05 / 96)$ were obtained from OASIS for 50 stations in the basin. The records consisted of temperature, dewpoint, cloud cover and windspeed. A series of quality checks was performed, including infilling of missing data using the nearest available record. Hourly precipitation data were obtained for the same period for parametrization simulations, and for validation of the radar rainfall data set used for model forcing.

\section{DISCHARGE}

Daily discharge records for the five parametrization catchments and intermediate and outlet stations along the Arkansas and Red Rivers were obtained from the relevant state USGS offices. The availability and quality of data is variable but coverage is more or less complete for all stations for the two year simulation period.

\section{Model set-up}

MODEL FRAMEWORK

The model is set up on a grid compatible with coupling to the UK Met. Office (UKMO) Unified Model, operating at 
mesoscale resolution. The grid is formed on regular 0.15 degree squares, but undergoes a rotation transformation. The effective grid size is then around $17 \mathrm{~km}$, and the basin is covered by 1932 squares, or UP-elements (see Fig. 2). The model parametrization procedure is as follows:

- the basin is classified into a number of domains, such that selected physiographic and hydrological properties are uniform within each domain;

- detailed parametrizations are performed for a catchment representative of each domain in terms of selected properties (see Ewen et al., 1999);

- each UP-element is then assigned parameter values according to which domain it lies within.

\section{CLASSIFICATION}

The Arkansas-Red River basin was classified into hydrological domains using cluster analysis. This was achieved using a two-stage unsupervised classification within GRASS. Various combinations of hydrologically important input thematic maps at $1-\mathrm{km}$ resolution were investigated. Acceptable results were obtained using five input map layers; elevation, variance of elevation (over $25 \mathrm{~km}^{2}$ area), peak vegetation greenness, duration of greenness and annual rainfall. Geological and functional land cover classifications were unsuitable for this type of analysis because of their discrete variables.

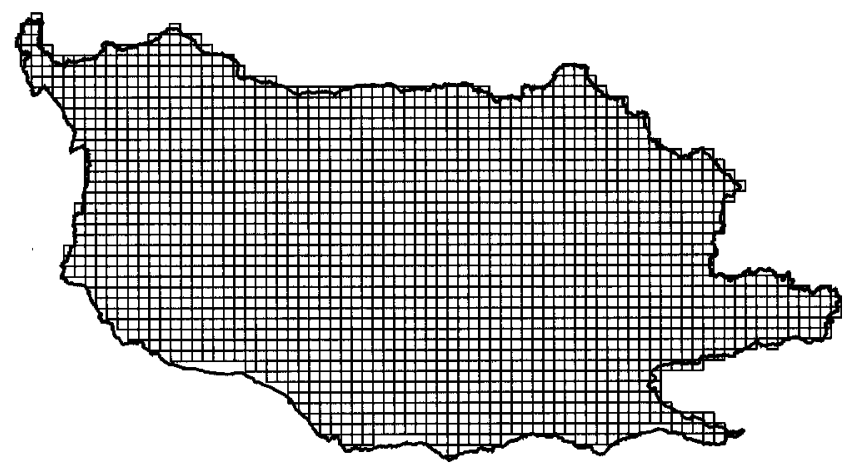

Fig. 2. Map of Arkansas-Red River basin with UP grid superimposed

The classification initially produced fifteen domains. Geographically adjacent domains were then merged to four for practicality. Sub-divisions according to hydrogeology were also considered and a fifth domain on the Mississippian limestone in the NE of the basin was created (Fig. 3). The five domains correspond roughly to established physiographic regions; Rocky Mountains, Great Plains, Central Lowlands, Ouachita Mountains and the Ozark Plateau.

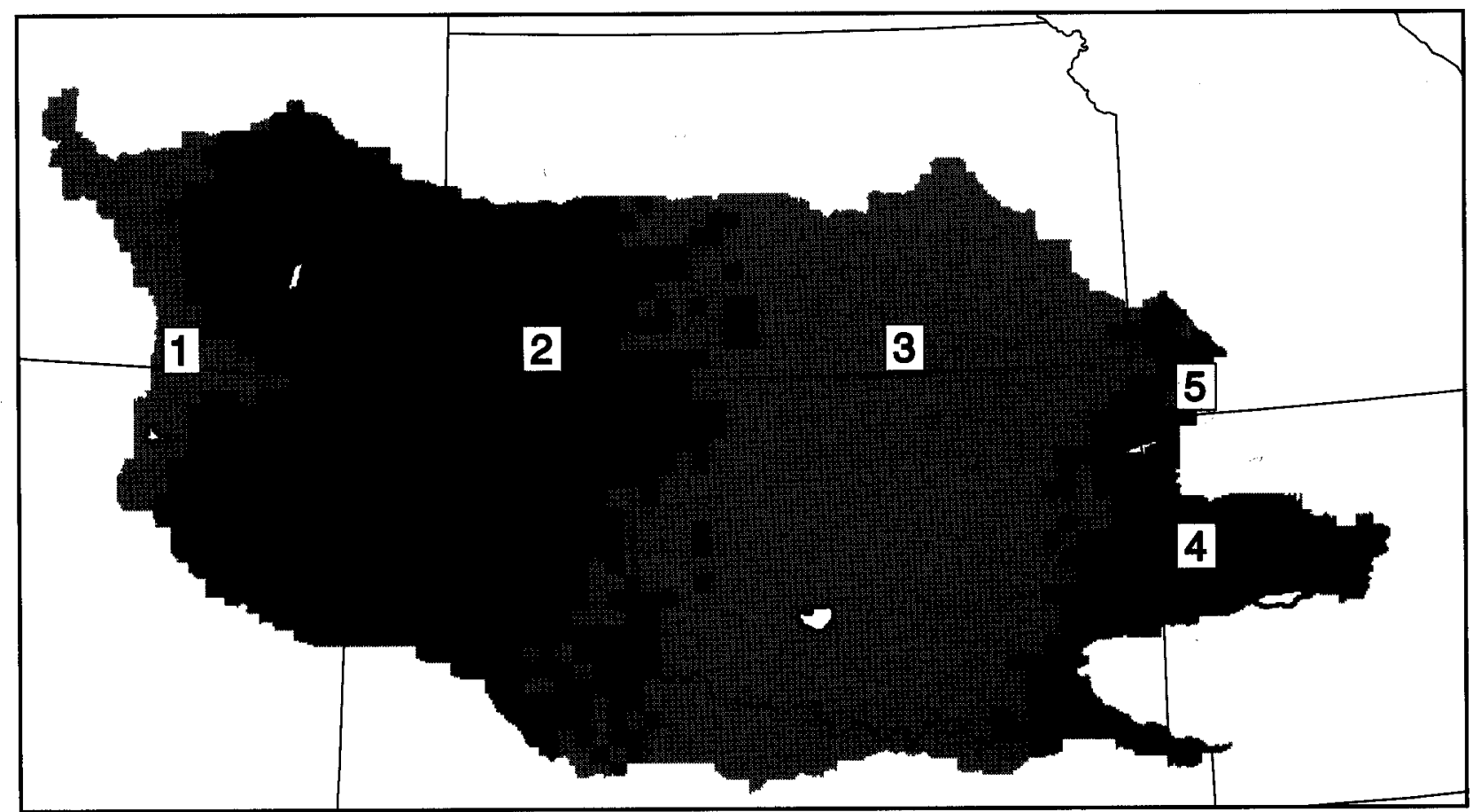

Fig. 3. Map of Arkansas-Red River basin showing the five hydrological domains, with the corresponding parametrization catchments: 1, Rocky mountains (Rayado Creek); 2 Great Plains (Crooked Arroyo); 3 Central Lomlands (Little Washita); 4 Ouachita Mountains (used parameters from McAlester catchment, see Emen et al., 1999); 5 Ozark Plateau (Flint Creek) 
Table 1. Summary properties of the four parametrization catchments

\begin{tabular}{llllll}
\hline Catchment & $\begin{array}{l}\text { Area } \\
\left(\mathbf{k m}^{2}\right)\end{array}$ & $\begin{array}{l}\text { Mean elevation } \\
(\mathbf{m})\end{array}$ & $\begin{array}{l}\text { Mean annual } \\
\text { rainfall }(\mathrm{mm})\end{array}$ & Dominant land cover & USGS Gauge No \\
\hline Rayado Creek, NM & 165 & 2837 & 510 & Evergreen forest & 07208500 \\
Crooked Arroyo, CO & 275 & 1370 & 405 & Open shrubland & 07122400 \\
Little Washita, OK & 600 & 392 & 768 & Cropland/natural & $\mathbf{0 7 3 2 7 5 5 0}$ \\
Flint Creek, OK & 296 & 350 & 1079 & Deciduous forest/cropland & $\mathbf{0 7 1 9 6 0 0 0}$ \\
\hline
\end{tabular}

\section{PARAMETRIZATION CATCHMENTS}

A small catchment (less than $1000 \mathrm{~km}^{2}$ in area) was selected in each of the domains (Table 1) according to data availability. The parametrization procedure and validation is described fully in Ewen et al., (1999).

\section{ATMOSPHERIC FORCING}

The model may be driven with data taken from observations or coupled to an atmospheric model. The spatial and temporal resolution of the rainfall data is of course critical to the representation of hydrological processes in the model. The results presented here were obtained using the highest obtainable resolution data set, with rainfall fields derived from radar data and meteorological data derived from the OASIS network.

\section{Rainfall input dataset}

ABRFC Stage III rainfall radar data (Smith et al., 1991) were processed to provide hourly input for the nearly 2-year simulation period, July 1994 - May 1996 inclusive. The ABRFC data are derived from the NEXRAD WSR88D network, giving complete coverage of the basin at hourly and 4- $\mathrm{km}$ resolution. The data have been calibrated and infilled by $A B R F C$ using gauge data. A co-ordinate transformation and resampling procedure was carried out, to produce hourly fields on the UP grid. Validations of the data set were performed against hourly gauge data, with generally satisfactory results. Some underestimation in the far north west of the basin was observed, and a number of artefacts are to be found in the spatial patterns. This data set, however, remains the best available at hourly resolution.

\section{Meteorological data}

The OASIS meteorological data were processed to provide vapour pressure deficit and net radiation inputs to UP for the calculation of potential evapo-transpiration (PET). Net radiation was calculated from hourly estimates of incoming and outgoing longwave and shortwave radiation. These estimates were made from hourly cloud cover, temperature and humidity observations, using empirical relations (Thompson et al., 1981, Doorenbos and Pruitt, 1984) together with calculated solar elevations and surface albedo estimated from land cover. Data were then allocated to the appropriate UP elements according to a Thiessen polygon method (see Fig. 4). Corrections were applied to the temperature data based on the UP element mean elevations using a basin-wide regression of temperature on elevation.

\section{GROUNDWATER MODEL}

The groundwater compartment of the UP element is treated in a different manner depending on whether it represents part of a larger regional aquifer or an aquifer which can be considered local to that element. Where the aquifer is local, upscaling is employed. Where the groundwater is part of a regional aquifer, a cruder, but more conventional, representation is employed. In this case, a finite difference model is used to represent the inter-element fluxes. Each cell in the grid represents the groundwater compartment of a single UP element, and the groundwater head values simulated are the spatially averaged head values within the element.

\section{CANOPY MODEL PARAMETERS}

Each UP element may contain up to three land cover types (plus bare soil) in specified area fractions. Four land cover types were considered across the basin, obtained from reclassification of the 1-km data base described earlier; evergreen forest, deciduous forest, grassland and cropland (see Fig. 5). The area fraction (within each UP grid square) of each of the three most dominant types was derived using the reclassified data set within GRASS. Vegetation parameters for the Penman-Monteith evapotranspiration model for each of the land cover types were taken from values reported in a range of literature. Values were taken to be time invariant within a season (Table 2) and were obtained for;

- aerodynamic resistance $r_{a}$, (not dependent on windspeed)

- minimum surface resistance, $\mathrm{r}_{\mathrm{smin}}$

- canopy storage capacity

- ground cover fraction

\section{ROUTING}

River discharge from each element is routed to the basin outlets using a network-width-function scheme developed 
Table 2. Vegetation parameters for the four land cover types. Values are given for three 'seasons': spring, day of year 29 to 118 ; summer, 119 to 301 ; winter, 302 to 28 .

\begin{tabular}{lllll}
\hline & $\begin{array}{l}\mathrm{r}_{\mathrm{a}} \\
\left(\mathrm{sm}^{-1}\right)\end{array}$ & $\begin{array}{l}\mathrm{r}_{\text {smin }} \\
\left(\mathrm{sm}^{-1}\right)\end{array}$ & $\begin{array}{l}\text { Canopy storage capacity } \\
(\mathrm{mm})\end{array}$ & Ground cover fraction \\
\hline Grassland & 606060 & 100130160 & 0.50 .50 .5 & 1.01 .00 .9 \\
Crops & 505050 & 80110140 & 0.60 .60 .6 & 1.00 .80 .0 \\
Deciduous & 101010 & 110130150 & 0.90 .90 .2 & 1.01 .01 .0 \\
Coniferous & 101010 & 110130150 & 0.90 .90 .9 & 1.01 .01 .0 \\
\hline
\end{tabular}

at the Institute of Hydrology (Naden et al., 1999). Discharge is routed through a number of intermediate points on the network (see Naden et al., 1999 and Fig. 1 for details).

\section{Results}

The UP simulation model produces for each grid square hourly values of a range of water storages (in the root zone, surface, canopy and ground water compartments as well as snow water equivalent) and water transfers (evaporation from interception, transpiration, surface runoff, groundwater runoff and percolation). Although distributed validation data do not exist for the entire basin, two validation strategies are possible. Firstly, a number of discharge records are available for catchments coincident with grid squares (including those grid squares used for the model parametrization). Secondly, a number of measures using aggregated quantities e.g. whole basin discharges and annual mean fields, can be used to assess the model's performance.

\section{GRID SCALE VALIDATION}

One of the motivations for the physical basis of the UP modelling system is the ability to reconstruct consistent sub-grid fields of simulation variables from the grid scale simulation variables (Sloan and Ewen, 1999). For this to be feasible, the model must be able to reproduce, correctly, the hydrological behaviour at the grid scale and one hour time step, rather than just the spatially aggregated behaviour (e.g. whole basin discharges) or time aggregated behaviour (e.g. mean runoff) which may be the case with lumped or calibrated models. This is also a requirement if the model is to be coupled to an atmospheric model.

Several grid scale validations have been performed across the basin; one is given in Fig. 6a showing the total runoff amount from the grid square containing the Little Washita catchment compared with the observed record. Note that whilst the overall behaviour is reproduced satisfactorily, some of the simulated peaks caused by intense rainfall are underestimated due to the use of spatially averaged radar rainfall data for driving the model. Shown in

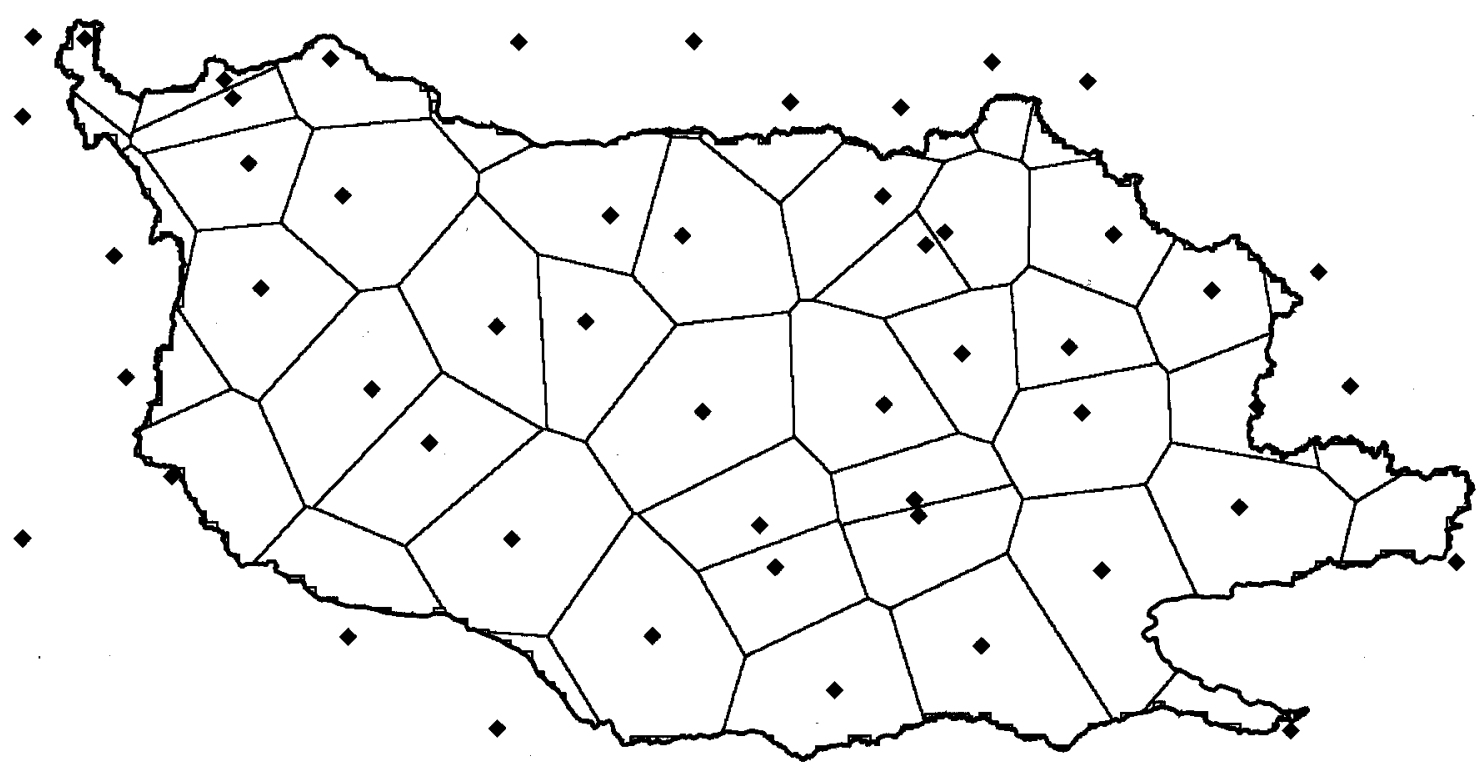

Fig. 4. Map shoming location of 61 meteorological stations for which records were obtained and the areas over which they mere applied. 


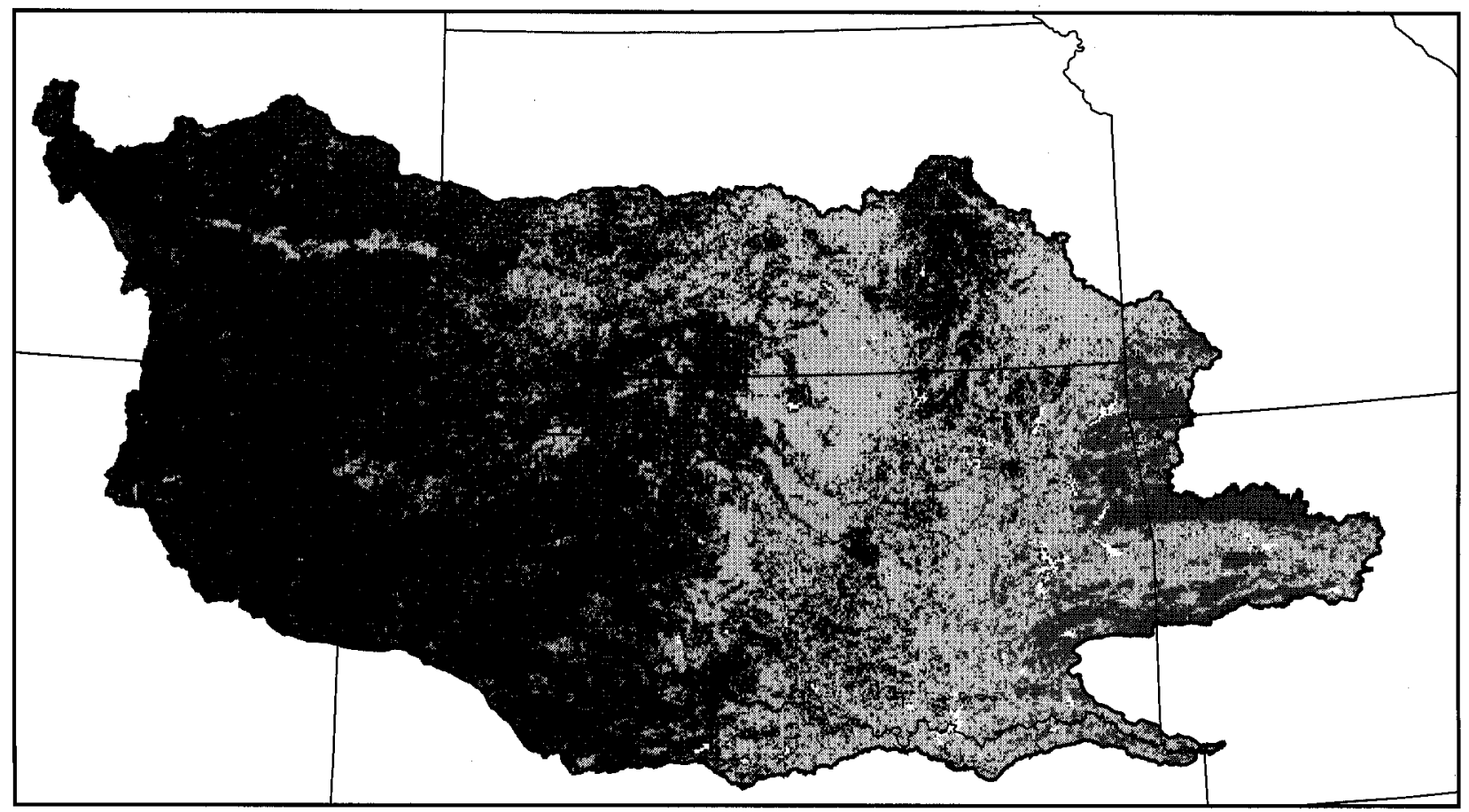

grass

deciduous woodland

evergreen woodland

agriculture

Fig. 5. Map shoming land cover at $1-\mathrm{km}$ resolution according to the classification used in UP.

Fig. $6 \mathrm{~b}$ is the grid-square soil moisture content. No validation data are available, but the series can be seen to be related to the runoff time series.

\section{VALIDATION USING AGGREGATED VARIABLES}

The whole basin discharges aggregated to the daily level are shown in Fig. 7 separately for the Arkansas and Red Rivers (Murray Dam and Index gauging stations, respectively). The discharge series shown for Murray Dam has been naturalized by the US Army Corps of Engineers. This series was found to differ significantly from the directly observed series, and was reasonably close to the simulated series with a Nash-Sutcliffe efficiency of 0.42 . Major management of flows was evident in the unnaturalized Murray Dam series, primarily in sustained flows before and after the major peak around day 380 . The major discrepancies between the simulated and naturalized flows are in the underestimation or smoothing of the largest peak flows, and may be ascribed to the spatially averaged rainfall inputs and/or uncertainties in the routing model parameters (see Naden et al., 1999 for further details).
A naturalized series for Index was not available for the simulation time period; reasonable agreement between the simulated and observed series is achieved, however. A notable discrepancy is the sustained observed flow either side of the peak flow at day 380 , which appears to be artificial and similar to that observed in the Murray Dam series before naturalization.

Maps of the annual totals of model input precipitation, simulated runoff and simulated evapotranspiration are shown in Fig. 8. Mass conservation is, of course, observed strictly in the model; the change in storage averaged across the basin for the two year simulation is only some $2 \mathrm{~mm}$, with basin-mean range between highest and lowest values of some $68 \mathrm{~mm}$. As expected, the spatial distribution of runoff follows the precipitation distribution.

Comparison with long term mean values is possible (for example, maps of runoff derived for the period 1951-1980). Figure 9 shows the mean ratio of runoff to precipitation from the simulation period (July 1994 - May 1996) compared with the observed. The distributions are in reasonable agreement; as expected, the long term mean fields show a smoother decrease from east to west than the 


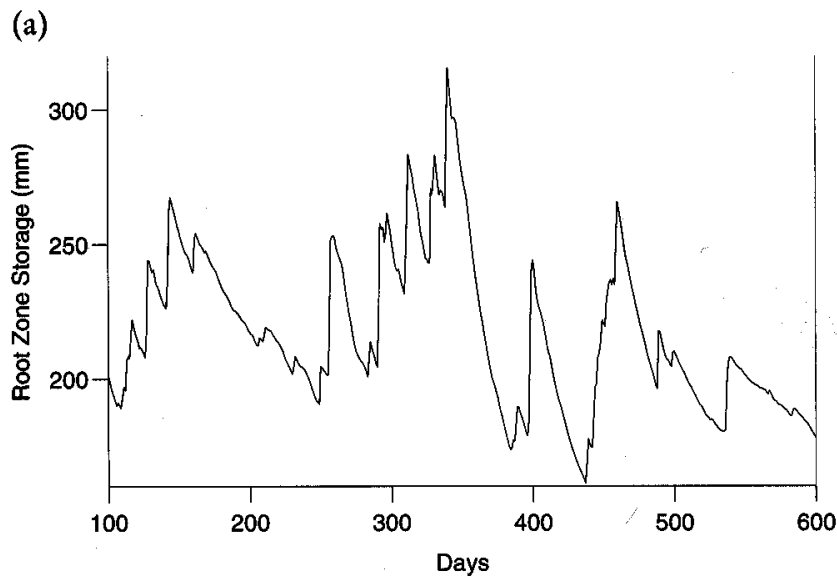

(b)

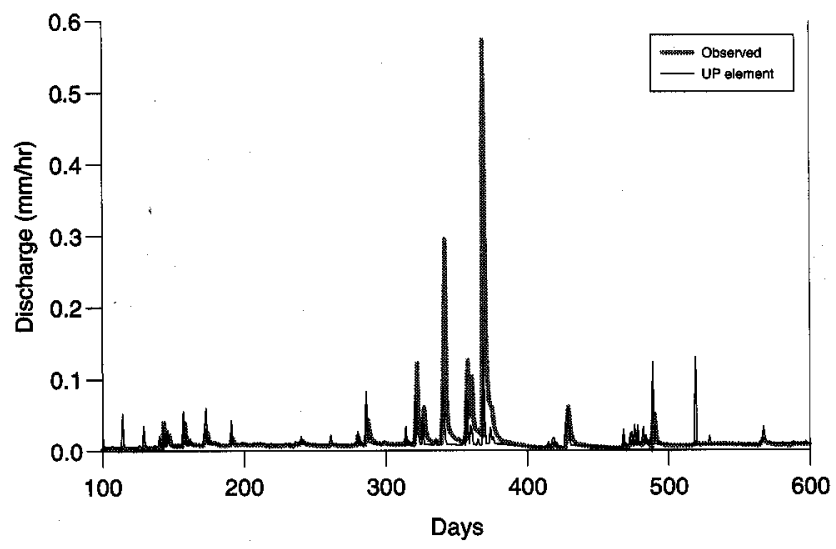

Fig. 6. (a) Observed river discharges for the Little Washita (OK) catchment with the simulated discharge for the corresponding grid square; (b) Simulated soil moisture for the same grid square. two-year simulation which is affected by individual rainfall events of limited spatial extent.

Time series of monthly basin mean rainfall, evapotranspiration and runoff may be used to study the overall water balance of the simulation and are shown in Fig. 10. These are the quantities most relevant to exchanges with an atmospheric model, and may be compared to the results from the PILPS2c workshop (Lohmann et al., 1998). Note that whilst the peaks in basin mean runoff correspond to the peaks in rainfall (July/August), the peak evapotranspiration occurs one month later, (August/September). This appears consistent with soil moisture storage supplying transpiration after the peak rainfall has passed, and PET has increased.

\section{Conclusions and discussion}

\section{ASSESSMENT OF PROGRESS}

The aims of this work were to develop and apply the UP modelling system to simulate the water budget and hydrological processes from the hillslope to the entire ARRB scale with reasonable computational efficiency whilst retaining a physical basis. Simple validations have been performed, but more detailed validations using a range of grid scale observed records remain to be done. No assessment of sensitivity of the simulation to the number of hydrological domains or form and accuracy of parametrizations has yet been done.

Nonetheless, a fair degree of success can be claimed. The model is substantially physically based: the parametrizations are derived mainly from small scale simulations using physically-based process models. The simulation model is fast and simple to run, and suitable for coupling

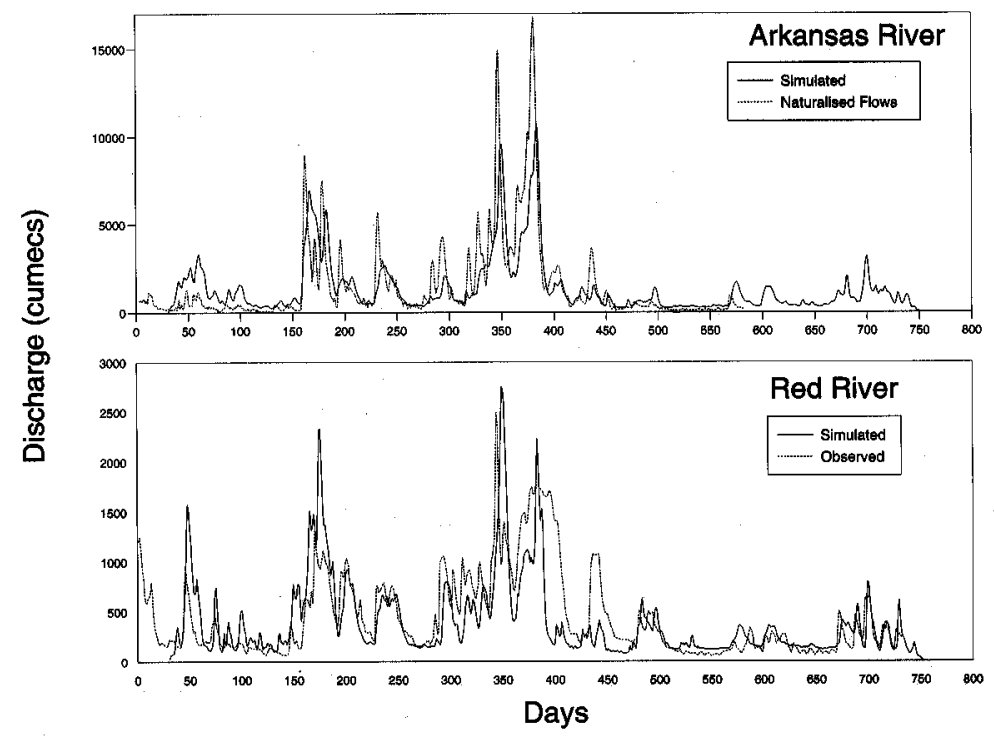

Fig. 7. River discharge at the outlets of the Arkansas and Red Rivers (Murray Dam and Index): comparison of simulated and observed daily discharges. The observed Murray Dam discharges have been naturalized: naturalized data for the Red River were not available for this time period. 
(a)
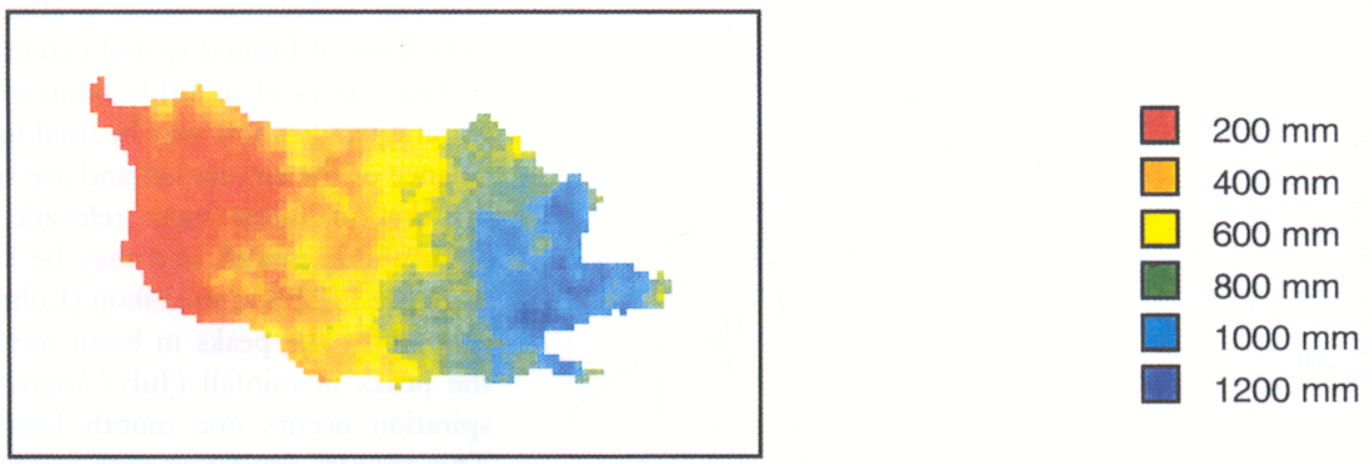

(b)

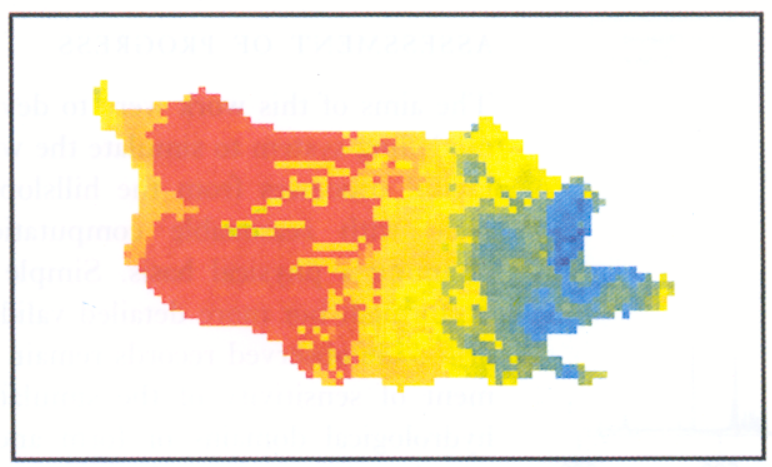

$<10 \mathrm{~mm}$

$100 \mathrm{~mm}$

$200 \mathrm{~mm}$

$300 \mathrm{~mm}$

$500 \mathrm{~mm}$

$\square>600 \mathrm{~mm}$

(c)

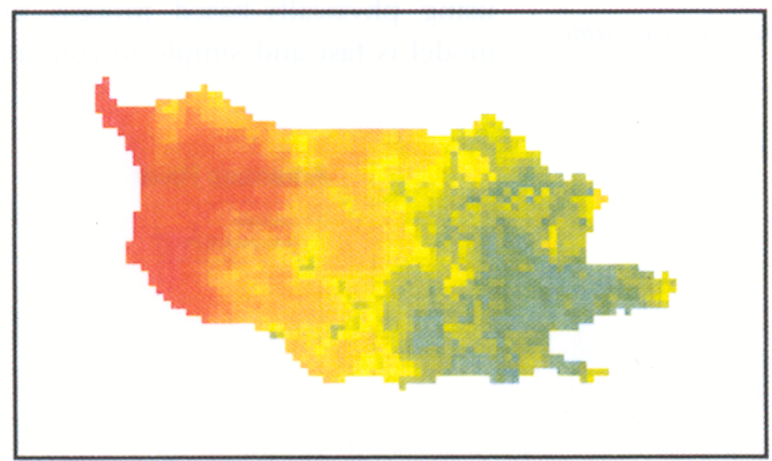

$200 \mathrm{~mm}$

$400 \mathrm{~mm}$

$600 \mathrm{~mm}$

$800 \mathrm{~mm}$

$1000 \mathrm{~mm}$

$1200 \mathrm{~mm}$

Fig. 8. Annual mean precipitation (a), runoff (b) and evapotranspiration (c) simulated by the UP model for the Arkansas and Red River basins.

to an atmospheric model: the 2-year hourly-timestep full basin simulation takes 4 hours on a Unix workstation. If the model were to be used for impact studies with changed land use or climate, a full sensitivity study would be required. However, the full range of hydrological processes have been included in the parametrizations, giving cause for optimism in regard to the capabilities of the model.

Application to other areas, and extension to global coverage remains a daunting task. Simple calibrated hydro- logical and land surface models have already been applied on a global scale. Their parametrizations are generally modified from calibrated values, based on coarse soil property and vegetation data and taking no account of groundwater or topography. What validations have been performed generally give great cause for concern. The UP system offers a great deal more physical basis for parametrization, but in turn imposes much greater demands on data supply. 

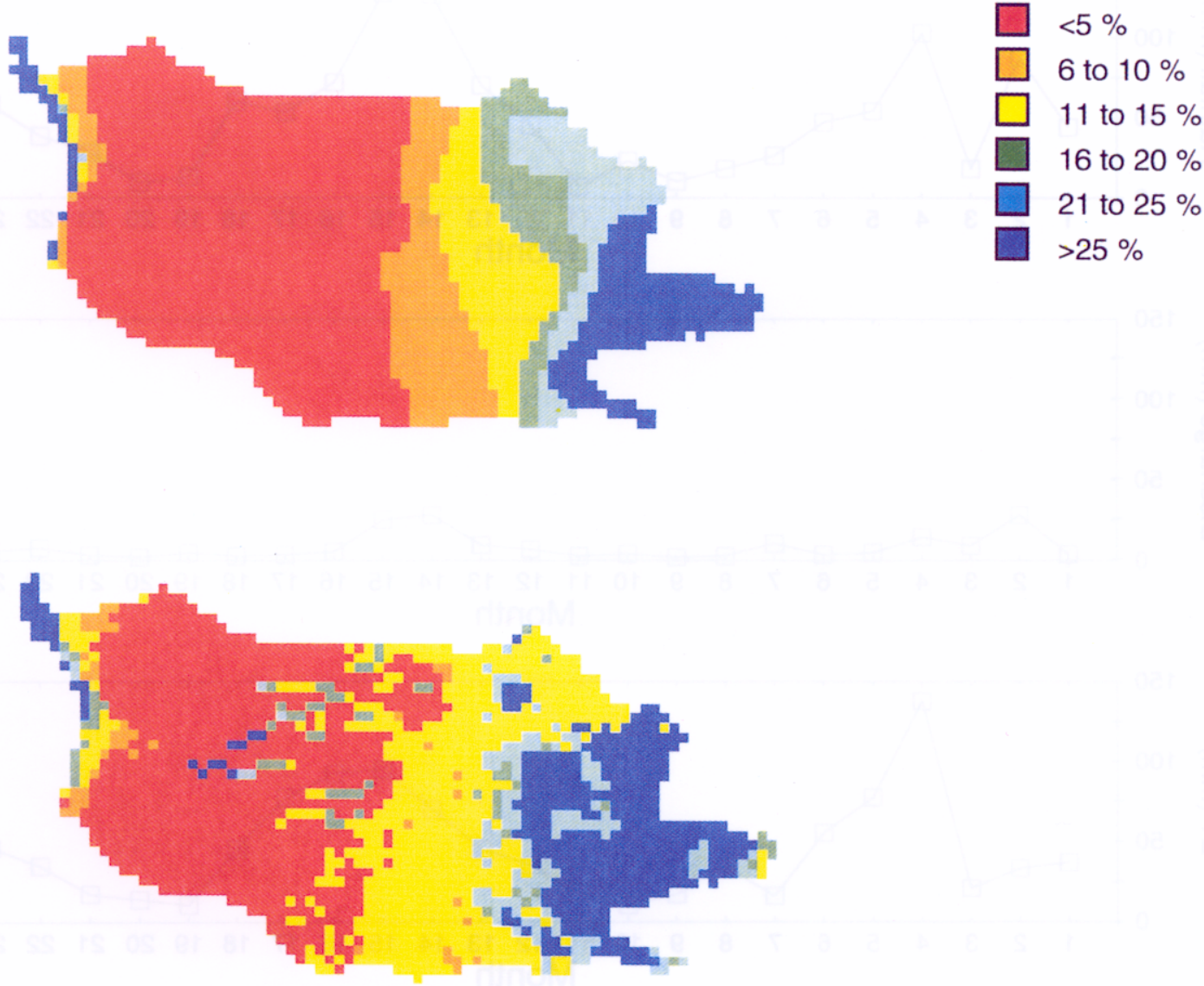

Fig. 9. Annual mean ratio of runoff to precipitation: comparison of simulated (Fuly 1994-May 1996, lower panel) and long term mean (1951-1980, upper panel) observed values.

\section{REMAINING PROBLEMS}

The problem of transferring parametrizations (or calibrations for non-physically-based models) between scales was noted earlier. Two procedures were used here to allow this transfer: classification and regionalization. The role of classification is to define a number of hydrological domains, so that catchments within the domains have a similar hydrological response. The hope is that a catchment can be selected within the domain which is representative (in terms of selected properties and corresponding model parameters) of the remainder of the domain. The role of regionalization is then to produce model parametrizations for all the UP elements in a domain, based on the parametrization for the representative catchment. This procedure should take into account any difference in spatial scale between the catchments and elements.

Two practical problems affect these procedures. Firstly, the degree to which an individual catchment is representative of others in the domain is dependent on the number and area of the domains and the degree of het- erogeneity present in the landscape. Secondly, the regionalization of parameters relies on the model parametrization being robust and independent of atmospheric forcing (e.g. annual rainfall). In this application, a relatively small number of domains was chosen due to practical considerations; there is doubt, therefore, that the responses of the parametrization catchments are representative. Furthermore, considerable variation in annual rainfall is found within domains (notably the Central Lowlands). This has necessitated several parametrizations within a domain.

\section{FUTURE WORK}

A full sensitivity analysis is the next step in this application. This will include testing of the individual parametrizations, and an assessment of how robust they are to transfer between scales and across ranges of precipitation.

Coupling the UP model offline to output from an atmospheric model is a next logical step within the GCIP programme. This would allow simulations over longer periods than at present, and would allow the assessment of 

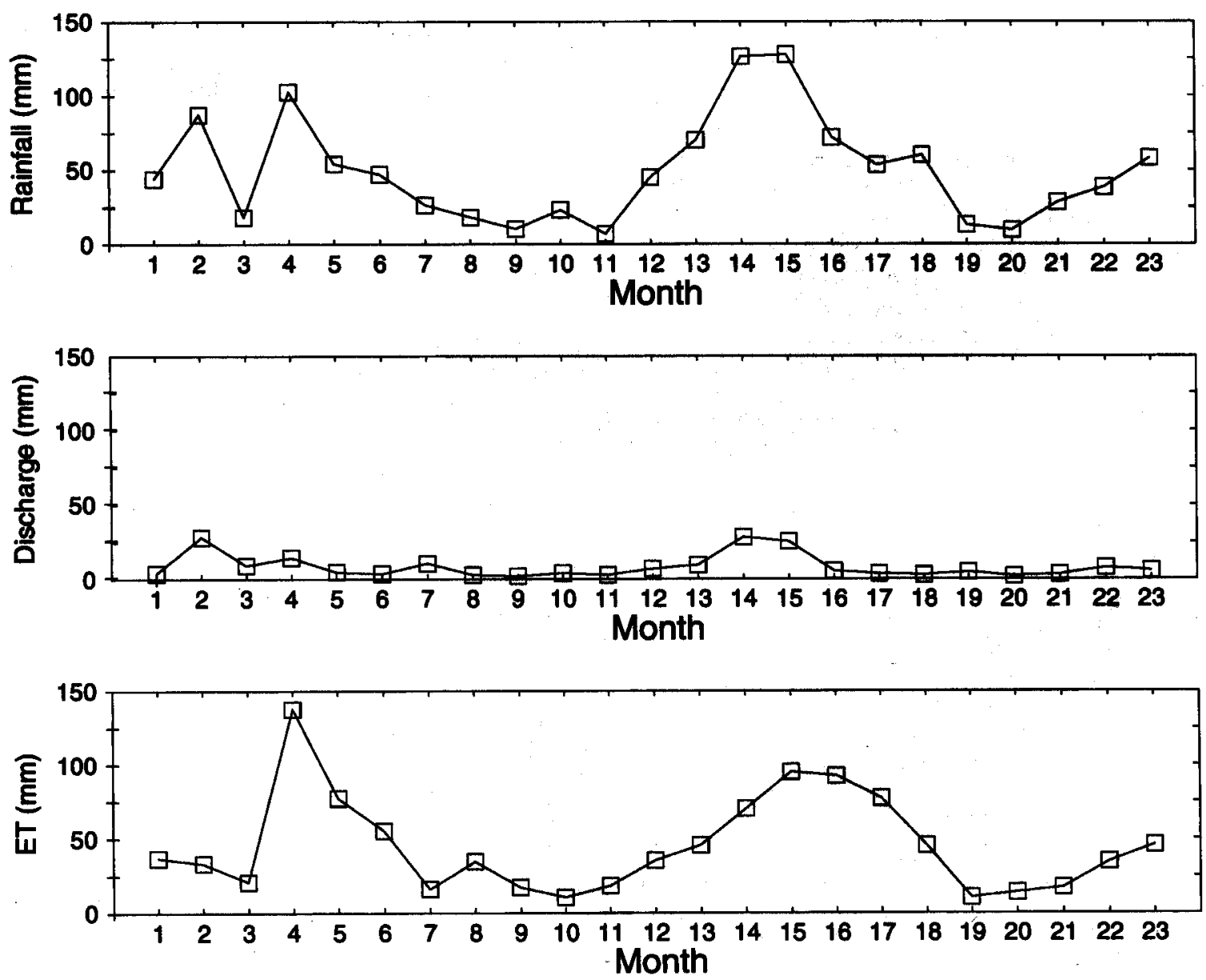

Fig. 10. Monthly time series of simulated monthly mean precipitation, runoff and evapotranspiration, starting in fuly 1994.

the effect of using atmospheric model precipitation output rather than observed radar fields. This would represent a likely substantial degradation of the quality and intensity distribution of the precipitation inputs, which in this work are already rather less intense than observed gauge records. This may have a substantial effect on the production of infiltration excess runoff, which is the dominant mechanism in the western part of the basin. These simulations will be performed with coupling off-line, but later simulations should be on-line, with the UP model replacing the Unified Model land surface parametrization.

The next step in model development will be towards streamlining the parametrization process which is at present very time consuming and data intensive. One possible area of development is incorporation of the system into a more generalized physically-based modelling framework, such as a new version of the physically-based distributed river basin modelling system SHETRAN planned at WRSRL (Ewen et al. in preparation).

\section{Acknowledgements}

This work was partly funded by TIGER under NERC grant GST/02/629, and was carried out using a UNIX workstation funded jointly by United Kingdom Nirex Limited and NERC grant GR3/E0009.

\section{References}

Abdulla, F.A. and Lettenmaier, D.P., 1997. Application of regional parameter estimation schemes to simulate the water balance of a large continental river, 7 . Hydrol., 197, 258-285.

Abdulla, F.A. and Lettenmaier, D.P., 1997. Development of regional parameter estimation equations for a macroscale hydrologic model, 7. Hydrol., 197, 230-257.

Dickinson, R.E., Henderson-Sellers, A., Kennedy, P.J. and Wilson, M.F., 1986. Biosphere-Atmosphere Transfer Scheme (BATS) for the NCAR community climate model: NCAR Technical Note, NCAR/TN-275+STR, National Center for Atmospheric Research, Boulder, Colorado.

Doorenbos, J. and Pruitt, W.O., 1984. Guidelines for predicting water requirements, FAO Irrigation and Drainage Paper, 24, FAO, Rome. 
Ewen, J., Parkin, G. and O'Connell, P.E., 1999. SHETRAN: a coupled surface/subsurface modelling system for $3 \mathrm{D}$ water flow and sediment and solute transport in river basins (in preparation).

Ewen, J., Sloan, W.T., Kilsby, C.G. and O'Connell, P.E., 1999. UP Modelling System for Large Scale Hydrology: Deriving Large-Scale Physically-Based Parameters for the ArkansasRed River Basin, Hydrol. Earth System Sci. 3, 125-136.

Gutentag, E.D., Frederick, J.H., Krothe, N.C., Luckey, R.R. and Weeks, J.B., 1984. Geohydrology of the high plains aquifer in parts of Colorado, Kansas, Nebraska, New Mexico, Oklahoma, South Dakota, Texas and Wyoming. USGS professional paper 1400-B.

Jorgensen, D.G., Helgesen, J.O. and Imes, J.L., 1993. Regional aquifers in Kansas, Nebraska, ans parts of Arkansas, Colorado, Missouri, New Mexico, Oklahoma, South Dakota, Texas and Wyoming. USGS professional paper 1414-B.

Lohmann, D., Lettenmaier, D.P., Liang, X., Wood, E.F., Boone, A., Chang, S., Chen, F., Dai, Y., Desborough, C., Dickinson, R.E., Duan, Q., Ek, M., Gusev, Y.M., Habets, F., Irannejad, P., Koster, R., Mitchell, K.E., Nasonova, O.N., Noilhan, J., Schaake, J., Schlosser, A., Shao, Y., Shmakin, A., Verseghy, D., Warrach, K., Wetzel, P., Xue, Y., Yang, Z-L. and Zeng, Q, 1998 The project for intercomparison of land-surface parameterization schemes (PILPS) phase 2(c): Arkansas Red-River basin experiment: 3. Spatial and temporal analysis of water fluxes, Glob. Planet. Change 19, 161-179.

Loveland, T.R., Merchant, J.W., Ohlen, D.O. and Brown, J.F., 1991, 'Development of a Land-Cover Characteristics Database for the Conterminous U.S.', Photogramm. Eng. Remote Sens., 57, 11, 1453-1463.
Miller, D.A. and White, R.A., 1998. A Conterminous United States Multilayer Soil Characteristics Dataset for Regional Climate and Hydrology Modeling, Earth Interactions, 2 (http://earthinteractions.org).

Naden, P., Broadhurst, P., Tauveron, N. and Walker, A., 1999, River routing for global climate models, Hydrol. Earth System Sci., 3, 109-124.

Running, S.W., Loveland, T.R., Pierce, L.L., Nemani, R. and Hunt, E.R., 1995. A Remote-Sensing Based Vegetation Classification Logic For Global Land-Cover Analysis, Remote Sens. Environ., 51, 1, 39-48.

Sloan, W.T. and Ewen, J., 1999. Modelling long term contaminant migration in a catchment at fine spatial and temporal scales using the UP system, Hydrol. Processes in press.

Smith, J.A., Seo, D.J., Baeck, M.L. and Hudlow, M.D., 1996, An Intercomparison Study Of Nexrad Precipitation Estimates, Wat. Resour. Res., 32, 2035-2045.

Snodgrass, R.J. and Faas, W.M., 1992. On-line Data Access at the National Climatic Data Center. Preprints, Eighth International Conference on Interactive Information and Processing Systems for Meteorology, Oceanography and Hydrology. American Meteorological Society, MA. 229-232.

Thompson, N., Barrie, I.A. and Ayles, M., 1981. The Meteorological Office rainfall and evaporation calculation system: MORECS, Hydrological Memorandum, Meteorological Office, UK.

Vankat, J.L., 1979. The Natural Vegetation Of North America. Wiley, Chichester, UK.

Wallis, J.R., Lettenmaier, D.P. and Wood, E.F., 1991. A daily hydroclimatological data set for the continental United States, Wat. Resour. Res., 27, 1657-1663. 